\title{
APPLICATION OF MULTIBODY SIMULATION FOR FATIGUE LIFE ESTIMATION
}

\author{
M. Kamal ${ }^{1}$, Md. Mustafizur Rahman ${ }^{1,2}$ and M.S.M. Sani ${ }^{1}$ \\ ${ }^{1}$ Faculty of Mechanical Engineering, Universiti Malaysia Pahang, \\ 26600 Pekan, Pahang Malaysia \\ ${ }^{2}$ Automotive Engineering Centre, Universiti Malaysia Pahang, \\ 26600 Pekan, Pahang Malaysia \\ Email: mustafizur@ump.edu.my
}

\begin{abstract}
In automobile design, the safety of passengers is of prime concern to the manufacturers. Suspension is one of the safety-related automotive systems which is responsible for maintaining traction between the road and tires, and offers a comfortable ride experience to the passengers by absorbing disturbances. One of the critical components of the suspension system is the knuckle, which constantly faces cyclic loads subjecting it to fatigue failure. This paper presents an evaluation of the fatigue characteristics of a knuckle using a gravel road profile acquired using a data acquisition system and standard SAE profiles for the suspension (SAESUS), bracket (SAEBRAKT) and transmission (SAETRN). The gravel road profile was applied as the input to a multi body simulation (MBS), and the load history for various mounting points of the knuckle is extracted. Fatigue life is predicted using the strain-life method. The instantaneous stress distributions and maximum principal stress are used for fatigue life predictions. From the results, the strut connection is found to be the critical region for fatigue failure. The fatigue life from loading extracted from gravel road MBS agreed well with the life prediction when standard SAE profiles were used. This close agreement shows the effectiveness of the load extraction technique from MBS. This method can also be effectively used for more complex loading conditions that occur during real driving environments.
\end{abstract}

Keywords: Fatigue; multibody simulation; suspension system; knuckle; strain-life method; maximum principal stress.

\section{INTRODUCTION}

One of the prime concerns in modern vehicle design is passenger safety. One technique of providing this is to install systems like air bags, seat belts, etc. Another technique is to design vehicle handling in such a way to ensure maximum control, even during extreme driving conditions/manoeuvers. The suspension system is one of the major aspects responsible for maintaining adequate vehicle traction at all times, to keep the vehicle under the driver's control (Rahman et al., 2006, 2009a; Yusof et al., 2012). Thus ensuring the safety by not allowing the vehicle to lose its grip on the road and skid off. This makes it extremely important and critical in the design of suspension so that it will perform according to the safety requirements and also so that no component will experience a structural failure during the design life, as this can cause fatal accidents (Liu, 2008; Domínguez Almaraz et al., 2010). In the current study the fatigue failure aspects of suspension system components are discussed. A suspension system 
comprises of a shock absorber and spring assembly, control arms and a knuckle. The knuckle is a critical component of the suspension system, and it is important to accurately predict its safe design life. The service loading of the suspension knuckle is time-varying in nature, structural loads are applied at more than one location and in more than one direction at the same time, resulting in complex stress and strain fields in the part (Azrulhisham et al., 2010). Due to these variable loads it is vital to estimate the fatigue life of the part to successfully determine the safe design life of the component under real world loading conditions (Rahman et al., 2009b; Zoroufi and Fatemi, 2006).

Fatigue life prediction relies on the stress/strain distribution in the component under study (Fatemi and Shamsaei, 2011; Zulkifli et al., 2011). For accurate fatigue life estimation, loads should be applied in three dimensions, making it close to the loads that the part encounters in the real world situation. Multi Body Simulation (MBS) is a good technique to calculate the load time history on the connection points of the knuckle on the suspension system (Kamal et al., 2012; Kang et al., 2010). In this paper, fatigue life estimation has been performed using the load time history calculated from MBS using a MBS software package, in which an actual gravel road profile at $60 \mathrm{~km} / \mathrm{hr}$, with standard SAE load distributions (SAEBRAKT, SAESUS and SAETRN) are considered as the input loading (Socie and Artwohl, 1978). FE linear stress simulations are performed using ANSYS software, where the loads are the forces calculated with MBS. For fatigue life estimation, ncode Designlife software is used. Proton SAGA front suspension is used in this study with the material of the knuckle is considered as FCD500-7 (Azrulhisham et al., 2010). Fatigue properties for fatigue life simulations are taken from ASTM A-536, which is equivalent to FCD500-7.

\section{METHODOLOGY}

\section{Multibody Simulation}

Multibody simulation (MBS) is a technique to study the kinetic/kinematic behaviour of mechanisms. Forces, moments, accelerations and the position of each components of the assembly can be monitored with respect to time in the form of time histories. These simulations are also termed rigid body simulations, which means that their shape does not change with the applied loads. FE stress analysis simulations are conducted separately to calculate the deformation in components due to dynamic loads. For which instantaneous loads can be extracted from the MBS results (Miao et al., 2009).

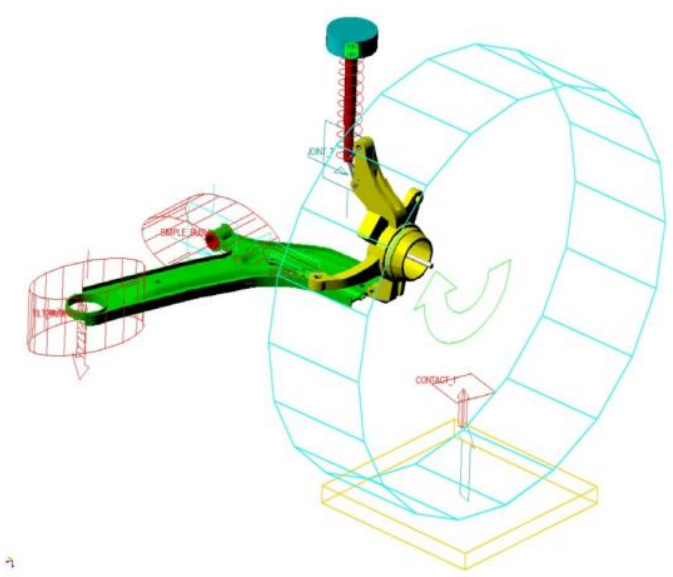

Figure 1. MBS model for MacPhearson strut type suspension. 
In the present study, the front suspension of a Proton Saga which is of a Macphearson strut type is under consideration. MBS modelling is conducted using the quarter car modelling approach (Figure 1). Real parts are used to develop the models for the knuckle and lower suspension arm, and the weight and diameter of the tire was determined from a Proton Saga tire. The tire is modelled as a rigid tire on the road profile of a gravel road at $60 \mathrm{Km} / \mathrm{hr}$ (Figure 2), the values for which are acquired using a test car, and the effect of tire flexibility is thus inherent in the profile data.

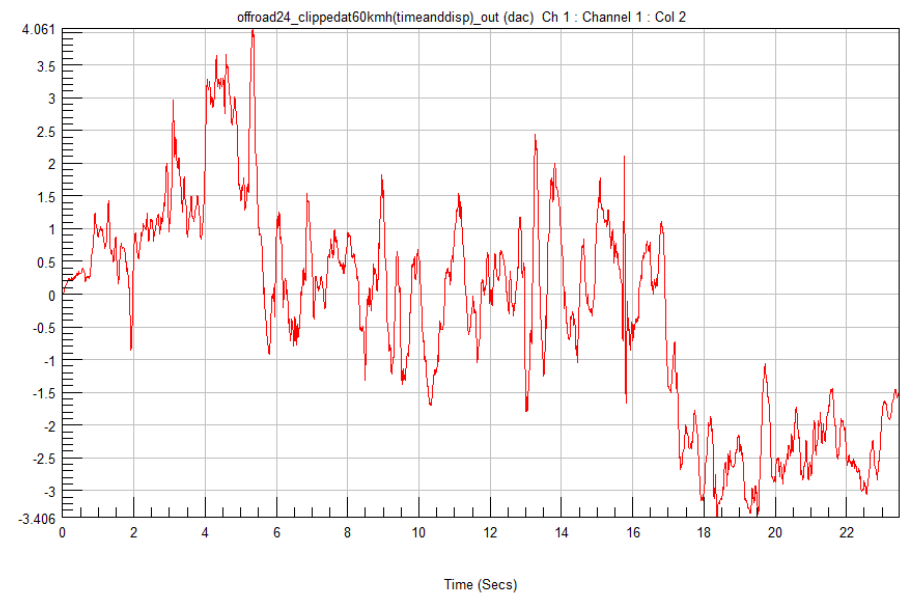

Figure 2. Gravel road profile at $60 \mathrm{~km} / \mathrm{hr}$ [tire deflection (mm) vs. time ( $\mathrm{sec})$ ].

\section{Finite Element Analysis}

A linear approach is used for FE stress analysis modelling of the knuckle. Figure 3 shows the load application points on the component. Instantaneous loads are extracted from the MBS results, where gravel road profile was used as the input (Figure 4), and separate load steps are used to apply each instantaneous load. The instant at which the maximum value of stress occurs is identified by running a stress analysis over all the load steps extracted from the MBS results, and then this maximum stress distribution was used to predict the fatigue life. An unstructured meshing scheme was used for mesh generation using Tet-10 elements, as they can accurately capture the typical geometric topology in a FEM model (Figure 5).

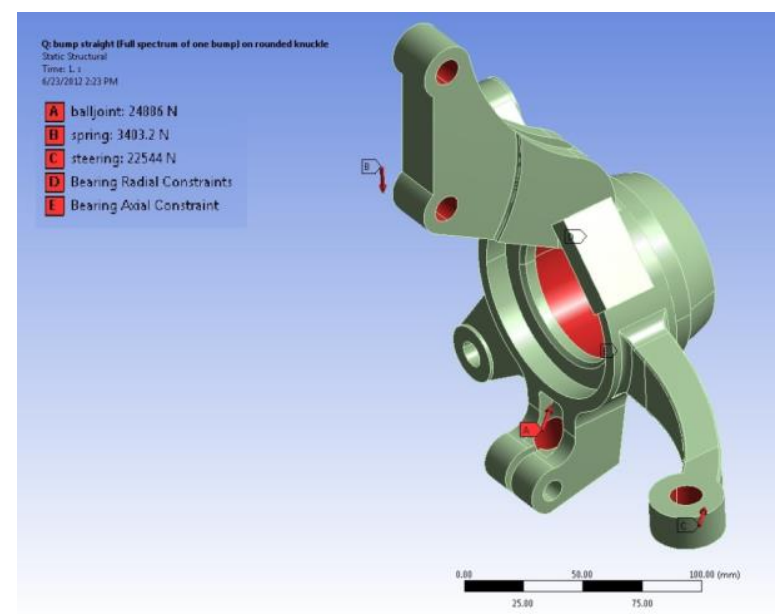

Figure 3. Location of applied loads and constraints. 


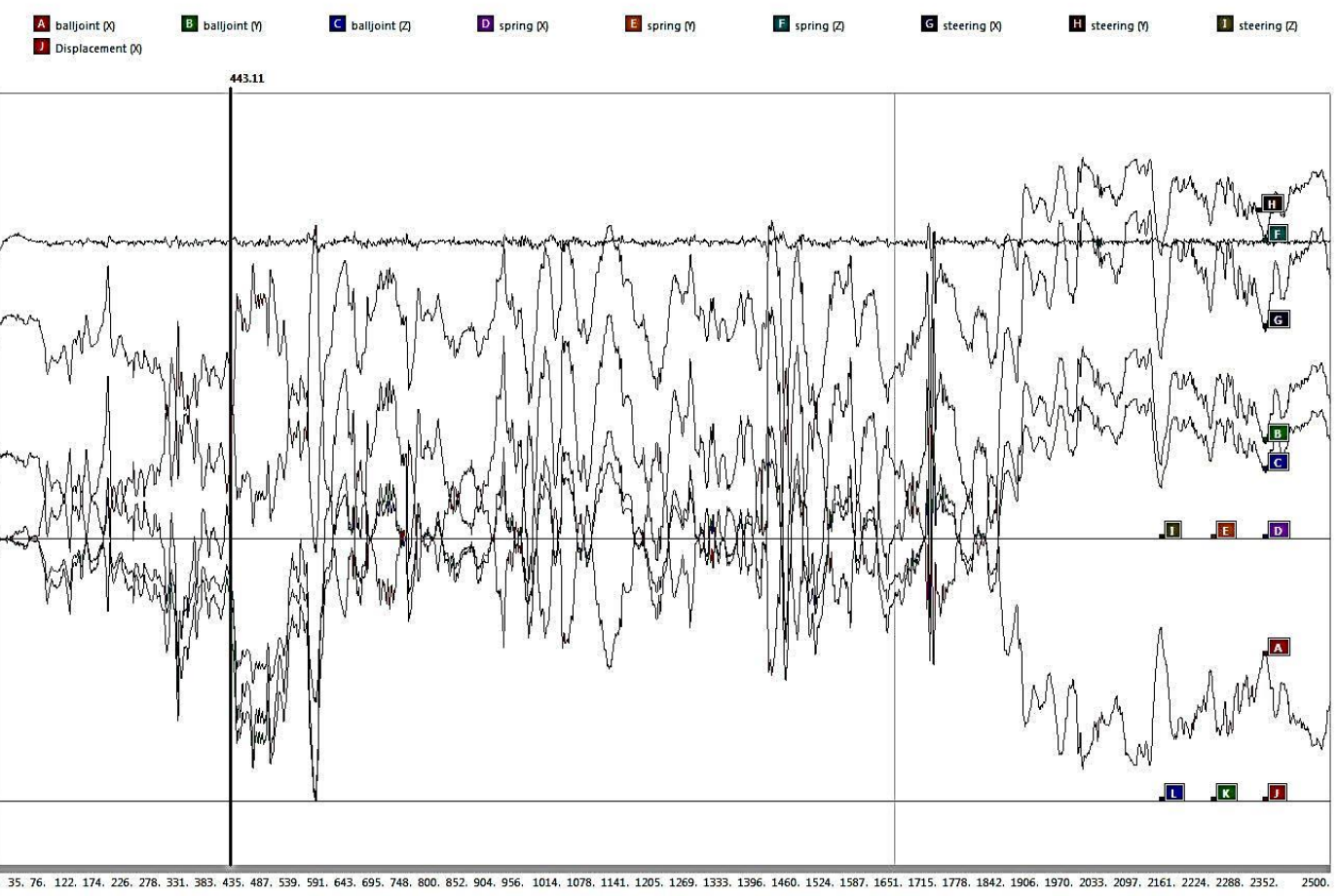

Figure 4. Forces due to gravel road at loading points on knuckle from MBS results.

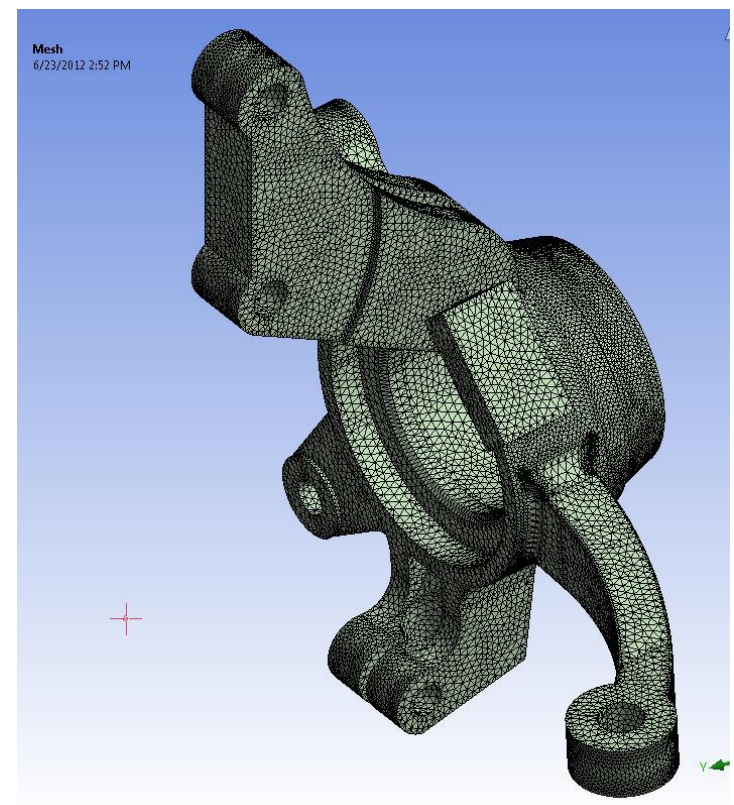

Figure 5. Unstructured mesh of knuckle using Tet-10 elements.

\section{Mesh Sensitivity Analysis}

A mesh size of reasonable accuracy and optimum solution time is determined by performing a mesh sensitivity analysis on the FE model (Rahman et al., 2008a, 2009c). A criterion for mesh convergence is based on the model, geometry, topology and analysis objectives. To capture the typical geometry and curved surfaces of the knuckle an unstructured tetrahedral meshing scheme was used with Tet10. The loading 
conditions and FEM model are shown in Figures 3 and 4. The convergence of stress is chosen as the main criteria for mesh size selection. The location with the maximum value of maximum principal stress is monitored for mesh convergence. Table 1 shows the stress variation with the change in global mesh size. The stress results show convergence at a mesh size of $1.15 \mathrm{~mm}$ [Figure 6(a)]. However, Figure 6(b) shows that after a mesh size of $1.25 \mathrm{~mm}$ there is a sharp increase in the number of nodes, which will place an excess load on the CPU and storage capacity. It is concluded that a mesh size of $1.15 \mathrm{~mm}$ is not acceptable on the basis of the simulation load, and hence a mesh size of $1.25 \mathrm{~mm}$ is selected as it has an acceptable FEM model size and solution time with reasonable accuracy.

Table 1. Variation in stress with change in global mesh size.

\begin{tabular}{|c|c|c|c|c|c|}
\hline \multirow[b]{2}{*}{$\begin{array}{l}\text { Global } \\
\text { mesh size } \\
(\mathrm{mm})\end{array}$} & \multirow[b]{2}{*}{ Total nodes } & \multirow[b]{2}{*}{$\begin{array}{l}\text { Total } \\
\text { elements }\end{array}$} & \multicolumn{3}{|l|}{ Stress } \\
\hline & & & $\begin{array}{l}\text { Von } \\
\text { Mises } \\
(\mathrm{MPa}) \\
\end{array}$ & $\begin{array}{l}\text { Tresca } \\
(\mathrm{MPa})\end{array}$ & $\begin{array}{l}\text { Max. } \\
\text { principal } \\
(\mathrm{MPa})\end{array}$ \\
\hline 2.25 & 112579 & 65378 & 315.5 & 323.6 & 324 \\
\hline 2 & 134040 & 77939 & 317 & 325.6 & 326.5 \\
\hline 1.75 & 170374 & 99446 & 319 & 327.5 & 329 \\
\hline 1.5 & 221905 & 130323 & 322 & 330.5 & 331.5 \\
\hline 1.25 & 303842 & 179316 & 324 & 332 & 333 \\
\hline 1.15 & 362442 & 215675 & 324.6 & 332.5 & 333.5 \\
\hline
\end{tabular}

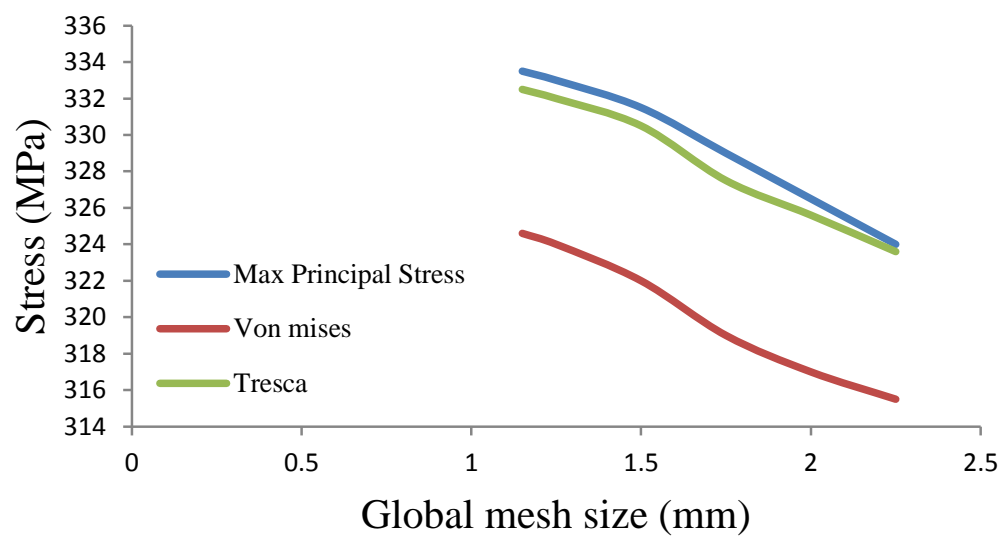

(a) Mesh size

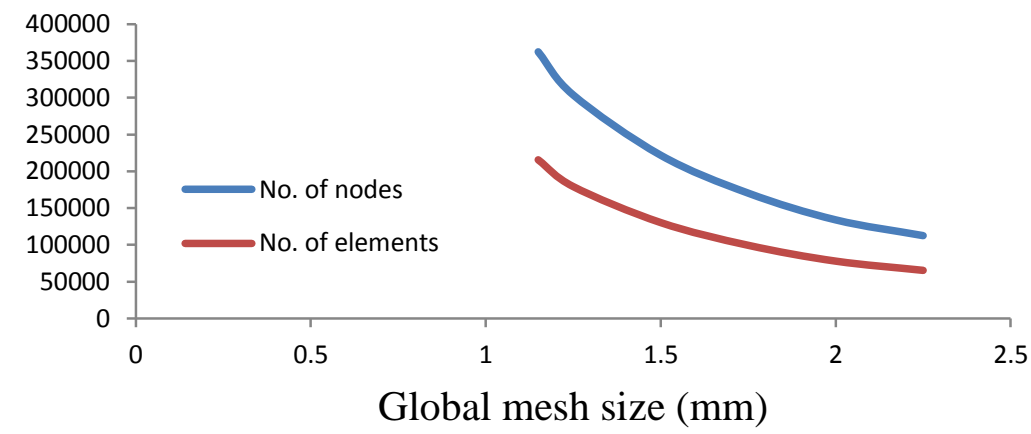

(b)

Figure 6. Global mesh size versus stress, numbers of nodes and elements. 


\section{Fatigue Analysis}

There are three methodologies used for fatigue analysis, i.e. the stress life approach, strain life approach and crack growth approach. The stress-life (S-N) method uses a relation between the nominal elastic stress and life to estimate the fatigue life. This method works accurately where only elastic stresses and strains are present (Rahman et al., 2008b). However, in many real world cases the parts under nominally cyclic elastic stresses may include stress concentration points, which can result in local cyclic plastic deformation (Bannantine et al.,, 1989). In accommodating plastic deformation effects, the strain-life (E-N) method uses local strains as the governing fatigue parameter. The local strain-life approach is referred to if the loading history is random and where the mean stress and the load sequence effects are thought to be of importance (Rahman et al., 2006, 2007). The strain-life approach involves techniques for converting the loading history, geometry and materials properties (monotonic and cyclic) input into a fatigue life prediction (Stephens et al., 2001). The prediction process involves sequential operations (Figure 7).

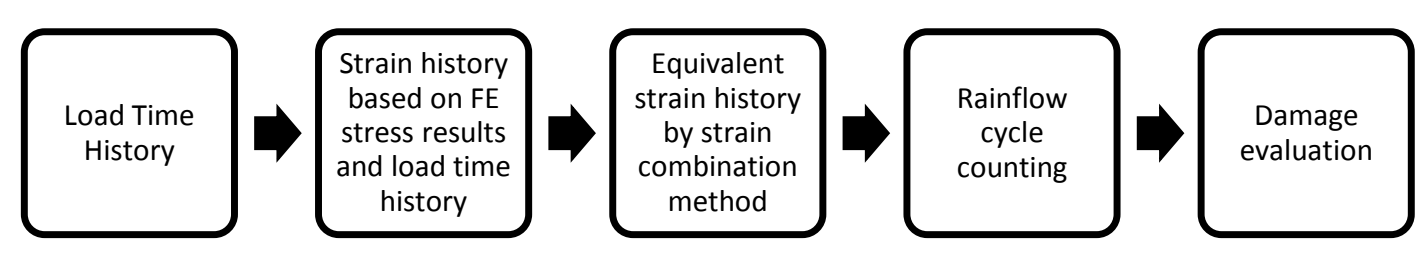

Figure 7. Strain life analysis steps.

Initially the stress and strain distribution are estimated, and then the load-time history is reduced using the rainflow cycle counting method (Matsuishi and Endo, 1968). The next step is to convert the reduced load time history into a strain time history using the finite element method, and also to calculate the stress and strain in the highlystressed area. Then the fatigue life is predicted using crack initiation methods. Fatigue damage is accumulated using the simple linear hypothesis proposed (Miner, 1945; Palmgren, 1924). Finally, the damage values for all cycles are summed until a critical damage sum (failure criteria) is reached. In the present study, the strain life analysis method is used to estimate fatigue damage. A strain-life curve is used to characterise the fatigue resistance of metals. These curves are derived from polished laboratory specimens tested under completely reversed strain controlled experiments. The relationship between the total strain amplitude $\left(\varepsilon_{\mathrm{a}}\right)$ and reversals to failure $(2 \mathrm{~N} f)$ can be mathematically expressed as the Coffin Mason Basquin equation (Eq. (1); Lee et al., 2005).

$$
\varepsilon_{a}=\frac{\sigma_{f}^{\prime}}{E}\left(2 N_{f}\right)^{b}+\varepsilon_{f}^{\prime}\left(2 N_{f}\right)^{c}
$$

where, $\mathrm{N} f$ is the fatigue life; $\sigma_{f}^{\prime}$ is the fatigue strength coefficient; $\mathrm{E}$ is the modulus of elasticity; $\mathrm{b}$ is the fatigue strength exponent; $\varepsilon_{f}$ is the fatigue ductility coefficient; and $\mathrm{c}$ is the fatigue ductility exponent.

The absolute maximum principal strain method is used to combine the component strains [Eq. (2)]. 


$$
\varepsilon_{A M P}=\varepsilon_{3} \text { if }\left|\varepsilon_{3}\right|>\left|\varepsilon_{1}\right| \text { otherwise } \varepsilon_{A M P}=\varepsilon_{1}
$$

where, $\varepsilon_{\mathrm{AMP}}$ is the absolute maximum principal strain, and $\varepsilon_{1}$ and $\varepsilon_{3}$ are the first and third principal strains.

The Morrow model is used for mean stress $\left(\sigma_{\mathrm{m}}\right)$ corrections (Eq. (3); Lee et al., 2005).

$$
\varepsilon_{a}=\frac{\left(\sigma_{f}^{\prime}-\sigma_{m}\right)}{E}\left(2 N_{f}\right)^{b}+\varepsilon_{f}^{\prime}\left(2 N_{f}\right)^{c}
$$

The Hoffman Seeger model (Hoffman and Seegar, 1989) is used for elastic plastic corrections. The cyclic material properties are used to calculate the elastic-plastic stressstrain response, and the rate at which fatigue damage accumulates due to each fatigue cycle.

\section{Materials Information}

The materials parameters required depend on the methodology being used. The mechanical properties of FCD500-7 and fatigue strain life properties of ASTM A-536 are listed in Table 2.

Table 2. Mechanical and cyclic properties of FCD500-7 and ASTM A536 (Azrulhisham

\begin{tabular}{|c|c|}
\hline Properties, Unit & Value \\
\hline \multicolumn{2}{|c|}{ Mechanical } \\
\hline Modulus, GPa, $E$ & 170 \\
\hline Yield strength, $\mathrm{MPa}, \sigma_{y}$ & 360 \\
\hline Ultimate strength, $\mathrm{MPa}, \sigma_{u}$ & 520 \\
\hline Density $\left(\mathrm{Kg} / \mathrm{m}^{3}\right)$ & 7140 \\
\hline \multicolumn{2}{|l|}{ Cyclic } \\
\hline Work hardening exponent,$n$ & 0.18 \\
\hline $\begin{array}{l}\text { Work hardening coefficient, } \\
\mathrm{MPa}, K\end{array}$ & 659 \\
\hline $\begin{array}{l}\text { Fatigue strength coefficient, } \\
\mathrm{MPa}, S_{f}^{\prime}\end{array}$ & 585 \\
\hline Fatigue strength exponent, $b$ & -0.075 \\
\hline Fatigue ductility exponent, $c$ & -0.751 \\
\hline Fatigue ductility coefficient, $E_{f}^{\prime}$ & 0.666 \\
\hline $\begin{array}{l}\text { Cyclic strain hardening } \\
\text { exponent, } n^{\prime}\end{array}$ & 0.14 \\
\hline $\begin{array}{l}\text { Cyclic strength coefficient, } \\
\mathrm{MPa}, K^{\prime}\end{array}$ & 877 \\
\hline
\end{tabular}
et al., 2010) 


\section{RESULTS AND DISCUSSION}

Multi body simulation was performed using the MBS software package in order to extract the time history of forces acting on the mounting points of a knuckle in a suspension system when subjected to a gravel road profile. Linear stress analysis was then performed utilising ANSYS software, to determine the stress and strain results from the finite element model, with the force-time history from the MBS results applied as separate load cases. The material is considered elastic and isotropic. The maximum stress load case in the knuckle is selected for fatigue life estimation. The maximum principal stress distribution is shown in Figure 8, and from the results a maximum principal stress of $333 \mathrm{MPa}$ is occurring in the location marked in the figure. Also, the von Mises and Tresca stresses at this location were found to be 324 and $332 \mathrm{MPa}$ respectively.

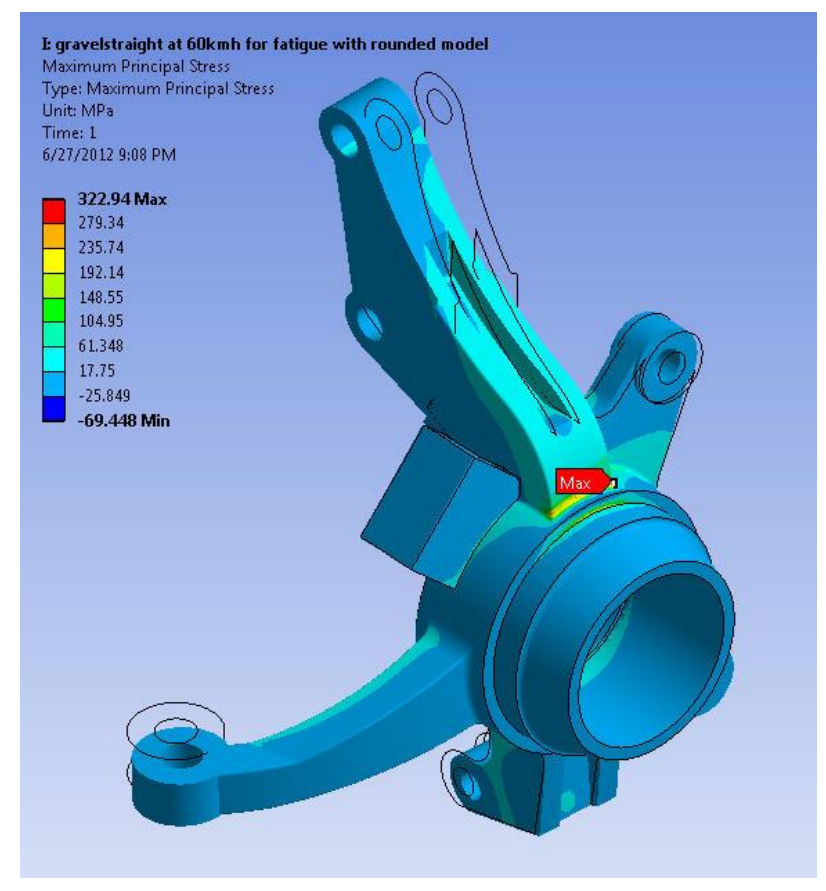

Figure 8. Maximum principal stress distribution

The knuckle is tested for fatigue life using finite element based fatigue analysis. It is made of FCD5007 (equivalent alloy ASTM A-536). A gravel road profile for a car travelling at $60 \mathrm{~km} / \mathrm{hr}$, and SAE standard profiles SAEBRAKT, SAESUS and SAETRN are considered as the loading time histories (Figure 2). The load case result with the maximum stress (Figure 8) is used as the stress distribution input in the fatigue life simulation for all loading time histories. The strain life method is used for fatigue life prediction, and the strain history is combined using the absolute maximum principal strain method. For elastic plastic correction the Hoffman Seegar method is used. The certainty of survival is set to be $50 \%$, which is a safe approximation for most cases. Figure 9 shows the fatigue life contours with the SWT method, and Table 3 shows the fatigue life with the application of various load profiles. From Table 3 it can be seen that SWT is the most conservative method with respect to Morrow and the no mean stress method for gravel roads and SAETRN. 


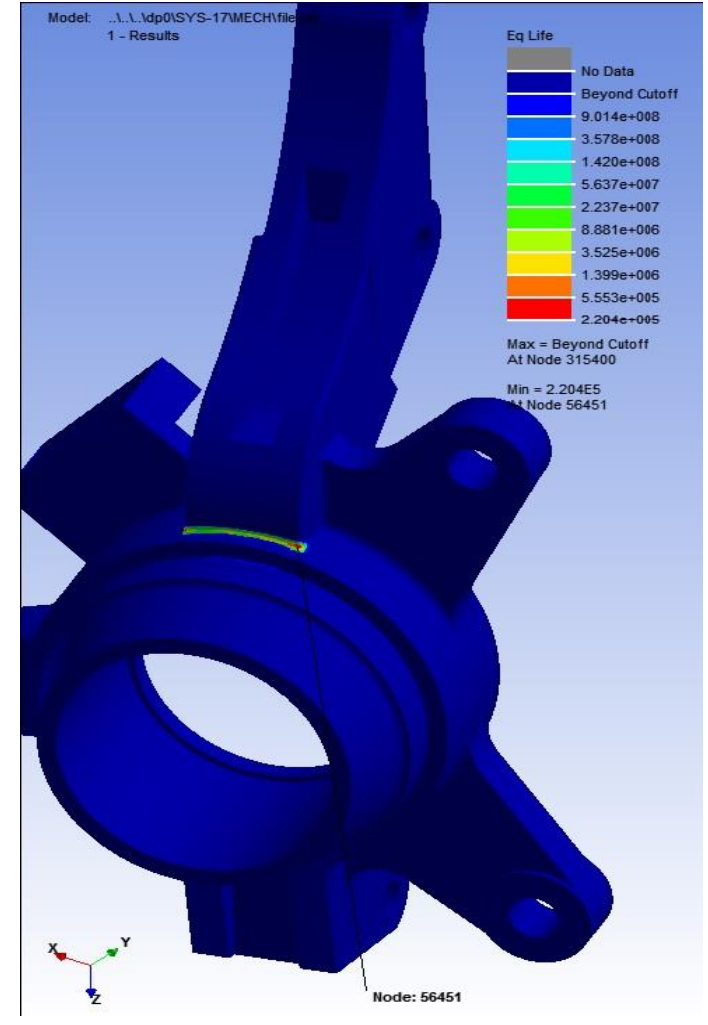

(a) Gravel road

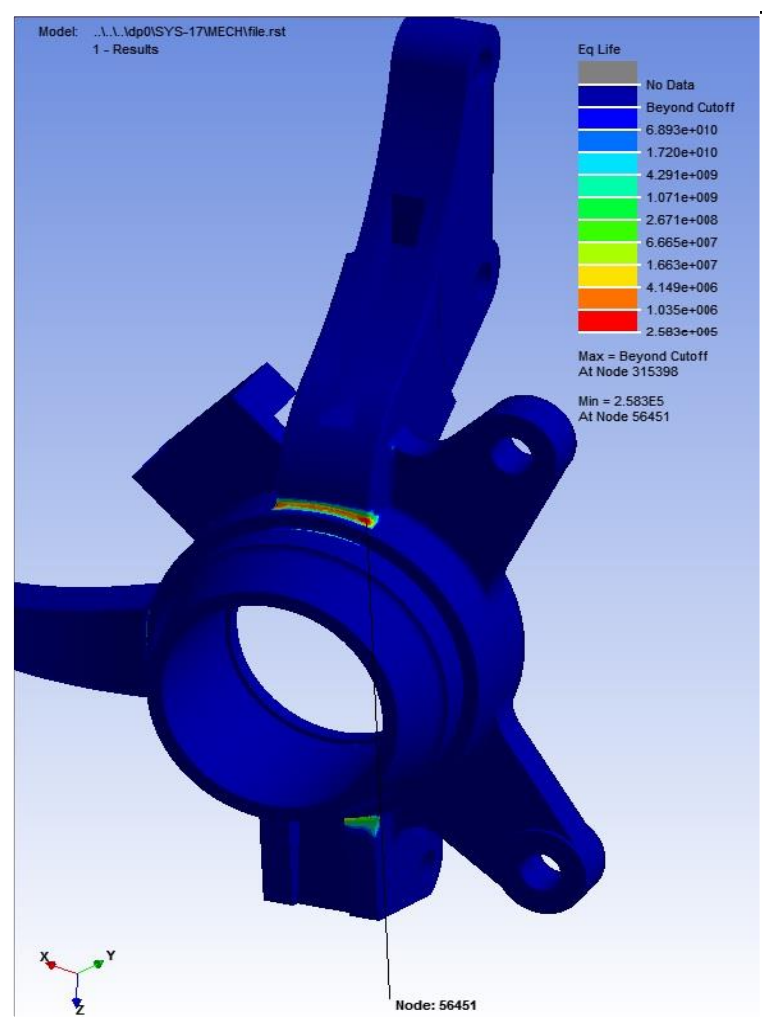

(c) SAESUS

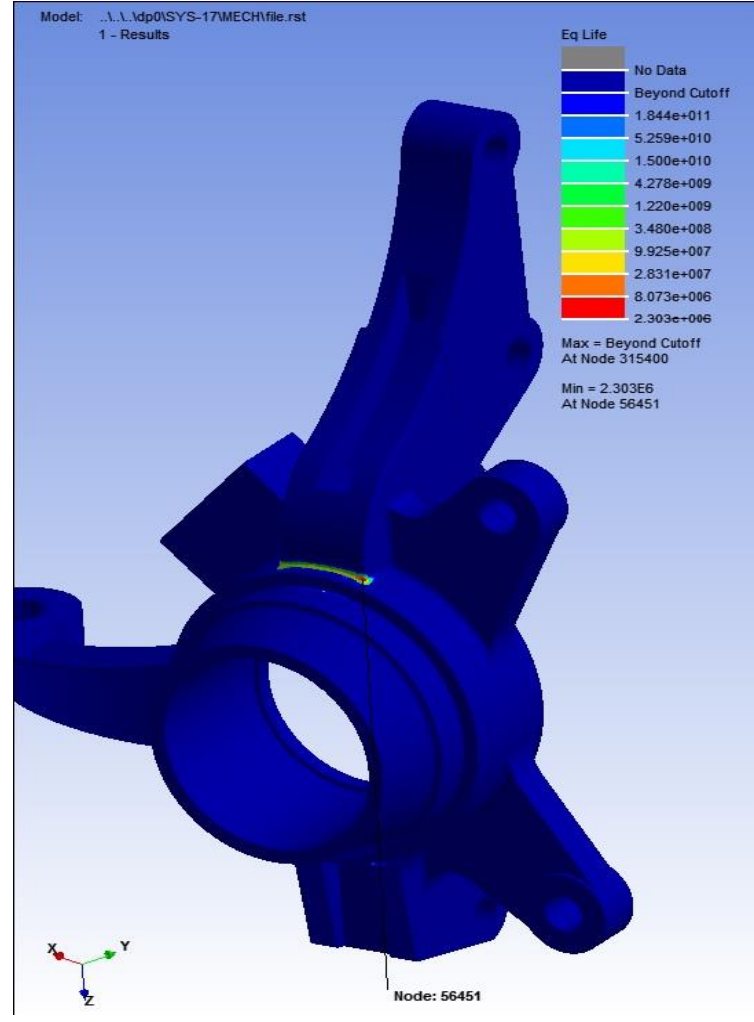

(b) SAEBRAKT

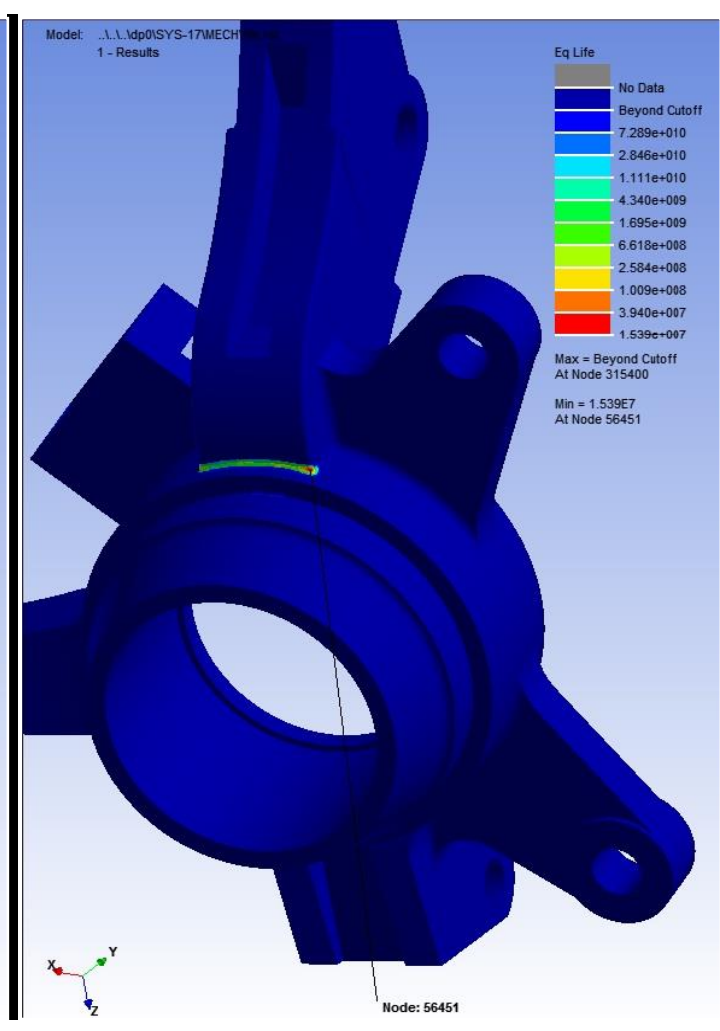

(d) SAETRN

Figure 9. Fatigue life in seconds of load time history with SWT method. 
Mean stress correction methods have very less effect in the case of SAESUS with comparison to the no mean stress correction result. Coffin Mason Basquin is the most conservative for SAEBRAKT and SAESUS. Also the results show the importance of using the mean stress correction methods, especially in case of tensile mean stress such as in the case of SAETRN. Here the resulting difference between the Morrow and SWT methods and the no mean stress method is appreciable, as the life increases by more than 100 percent from $268.4 \times 10^{5}$ and $153.9 \times 10^{5}$ to $755 \times 10^{5} \mathrm{sec}$ respectively. The other loading profiles used in the study have negative or near zero mean stresses, which renders the effect of the mean stress correction negligible. This is in agreement with the published literature (Dowling et al., 2009, Rahman et al., 2009c, Stephens et al., 2001). Moreover it is important to note that the SAE standard loading histories are essential for use in fatigue life prediction in the early design phase of components as they reduce time and resources; but in the final testing and determination of the service life of components the actual loading conditions, i.e. real road profiles where the vehicle is intented to be used, should be acquired. As seen in the results, the fatigue life for a gravel road is close to the SAESUS loading profile but not same, even less when the SWT method is used, this difference can increase under other actual loading conditions.

Table 3. Fatigue life at critical locations of node (56451) for various loading histories.

\begin{tabular}{cccc}
\hline Load Profiles & \multicolumn{3}{c}{ Fatigue life $(\mathrm{sec}) \times 10^{5}$} \\
\hline Mravel Road & 2.807 & SWT & Coffin Mason \\
SAEBRAKT & 25.95 & 2.204 & 3.193 \\
SAESUS & 2.581 & 23 & 21.79 \\
SAETRN & 268.4 & 2.583 & 2.254 \\
\hline
\end{tabular}

\section{CONCLUSION}

In this study an automotive suspension system knuckle is analysed for fatigue life estimation using ncode Designlife software and stress analysis using ANSYS software. Multi Body Simulation (MBS) is performed with a MBS software package to generate load time histories from an actual gravel road profile. The material of the knuckle considered is FCD500-7 (equivalent to ASTM A536). Loads applied to the FEA model are extracted from MBS results in the form of a time history. The linear stress analysis for every instance of the extracted force is performed, and then the stress distribution where the maximum stress occurs is selected and used for fatigue life prediction. Fatigue life is predicted using four load distributions, including an actual gravel road profile, SAEBRAKT, SAESUS and SAETRN. The results show that fatigue life is highly dependent on the variable amplitude loading, and also the tensile mean stress has a detrimental effect on the predicted fatigue life. The study also shows that the use of MBS to extract the component loads for fatigue analysis is an accurate technique to obtain very close to actual stress distributions, which is simple and results in an increase in confidence when selecting the damaging stress cases for fatigue life estimation. The predicted fatigue life for an actual gravel road which is used as the input to MBS results in a fatigue life which is in close agreement with the SAESUS loading distribution. 


\section{REFERENCES}

Azrulhisham, E.A., Asri, Y.M., Dzuraidah, A.W., Abdullah, N.M., Shahrum, A. and CheHassan, C.H. 2010. Evaluation of fatigue life reliability of steering knuckle using Pearson parametric distribution model. International Journal of Quality, Statistics, and Reliability, 816407: 1-8.

Bannantine, J.A., Comer, J.J. and Handrock, J.L. 1989. Fundamentals of metal fatigue analysis. New York: Prentice Hall.

Domínguez Almaraz, G.M., Guzmán Tapia, M., Tapia Silva, E.E. and Cadenas Calderón, E. 2010. Fatigue life prediction based on macroscopic plastic zone on fracture surface of AISI-SAE 1018 steel. International Journal of Automotive and Mechanical Engineering, 1: 29-37.

Dowling, N.E., Arcari, A. and Vita, R.D. 2009. Mean stress relaxation during cyclic straining of high strength aluminum alloys. International Journal of Fatigue, 31: 1742-1750.

Fatemi, A. and Shamsaei, N. 2011. Multiaxial fatigue: An overview and some approximation models for life estimation. International Journal of Fatigue, 33:948-958.

Hoffman, M. and Seeger, T. 1989. Estimating multiaxial elastic-plastic notch stresses and strains in combined loading. In: Brown MW, Miller KJ, editors. Biaxial and multiaxial fatigue, EGF3. London: Mechanical Engineering Publications, pp. 324.

Kamal, M., Rahman, M.M. and Rahman, A.G.A. 2012. Fatigue life evaluation of suspension knuckle using multi body simulation technique. Journal of Mechanical Engineering and Sciences, 3: 291-300.

Kang, D.O., Park, K., Heo, S.J., Ryu, Y. and Jeong, J. 2010. Development and application of VPG simulation technique based on equivalent virtual road profile. International Journal of Precision Engineering and Manufacturing, 11(2): 265-272.

Lee, Y.L., Pan, J., Hathaway, R.B. and Barkey, M.E. 2005. Fatigue testing and analysis (Theory and practice). Burlington: Elsevier Butterworth-Heinemann.

Liu, Y. 2008. Recent innovations in vehicle suspension systems. Recent Patents on Mechanical Engineering, 1: 206-210.

Matsuishi, M. and Endo, T., 1968. Fatigue of metals subjected to varying stress. Japan Society of Mechanical Engineers, Fukuoko, Japan.

Miao, B., Zhang, W., Zhang, J. and Jin, D. 2009. Evaluation of railway vehicle car body fatigue life and durability using multi-disciplinary analysis method. International Journal of Vehicle Structures \& Systems, 1(4): 85-92.

Miner, A. 1945. Cumulative damage in fatigue. Journal of Applied Mechanics, 12:159164.

Palmgren, A., 1924. Durability of ball bearings. ZVDI, 68(14): 339-341.

Rahman, M.M., Ariffin, A.K., Jamaludin, N. and Haron, C.H.C. 2006. Influence of surface treatments on fatigue life of a free piston linear generator engine component using random loading. Journal of Zhejiang University of Science Part A, 7(11):1819-1830.

Rahman, M.M., Ariffin, A.K., Jamaludin, N. and Haron, C.H.C. 2007. Finite element based durability assessment of a free piston linear engine component. Journal of Structural Durability and Health Monitoring, 3(1): 1-13. 
Rahman, M.M., Ariffin, A.K., Jamaludin, N., Abdullah, S. and Noor, M.M. 2008a. Finite element based fatigue life prediction of a new free piston engine mounting. Journal of Applied Sciences, 8(9): 1612-1621.

Rahman, M.M., Ariffin, A.K., Abdullah, S., Noor, M.M., Bakar, R.A. and Maleque, M.A. 2008b. Finite element based fatigue life prediction of cylinder head for two-stroke linear engine using stress-life approach. Journal of Applied Sciences, 8(19): 3316-3327.

Rahman, M.M., Kadirgama, K., Noor, M.M., Rejab, M.R.M. and Kesulai, S.A. 2009a. Fatigue life prediction of lower suspension arm using strain-life approach. European Journal of Scientific Research, 30(3): 437-450.

Rahman, M.M., Ariffin, A.K., Rejab, M.R.M., Kadirgama, K. and Noor, M.M. 2009b. Multiaxial fatigue behavior of cylinder head for a free piston linear engine. Journal of Applied Sciences, 9(15): 2725-2734.

Rahman, M.M., Ariffin, A.K., Abdullah, S., Noor, M.M. and Bakar, R.A. 2009c. Durability assessment of cylinder block for two stroke free piston linear engine using random loading. American Journal of Applied Sciences, 6(4): 726-735.

Socie, D.F. and Artwohl, P.J. 1978. Effect of spectrum editing on fatigue crack initiation and propagation in notched member. Report of the Fracture Control Program, University of Illinois, FCP-31.

Stephens, R.I., Fatemi, A., Stephens, R.R. and Fuchs, H.O. 2001. Metal fatigue in engineering. 2nd ed. New York: John Wiley \& Sons.

Yusof, M.F.M., Jamaludin, N., Abdullah, S., Hanafi, Z.H. and M.S.M. Zain. 2012. Monitoring and assessment of acoustic emission signatures during fatigue mechanism of API5LX70 gas pipeline steel. Journal of Mechanical Engineering and Sciences, 2: 237-250.

Zoroufi, M. and Fatemi, A. 2006. Experimental durability assessment and life prediction of vehicle suspension components: a case study of steering knuckles. Proceedings of the Institution of Mechanical Engineers, Part D, 220(11): 15651579.

Zulkifli, A., Ariffin, A.K. and Rahman, M.M. 2011. Probabilistic finite element analysis on vertebra lumbar spine under hyperextension loading. International Journal of Automotive and Mechanical Engineering, 3: 256-264. 